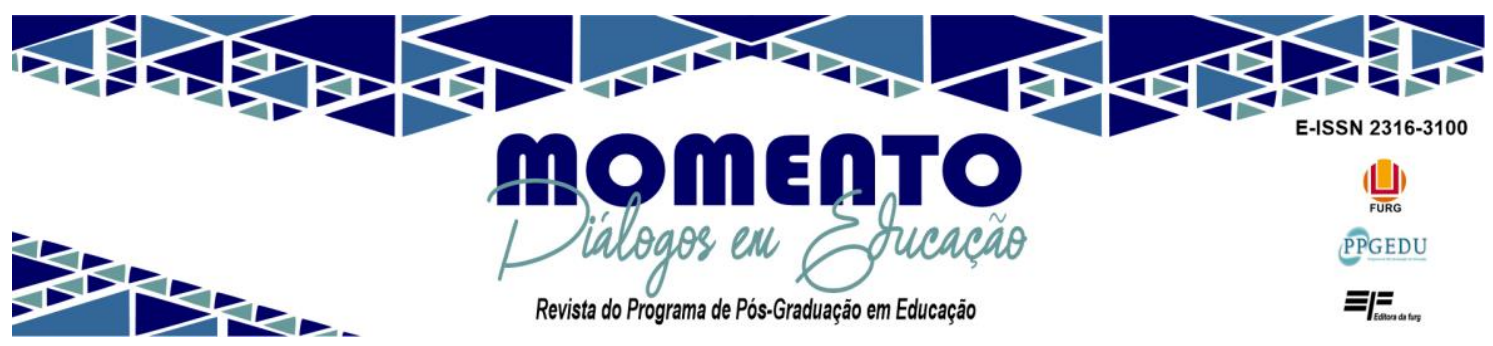

\title{
MARCOS REFERENCIAIS DE APROXIMAÇÕES ENTRE TEORIA CRÍTICA DE CURRÍCULO E EDUCAÇÃO INCLUSIVA
}

\author{
Cleusa Inês Ziesmann ${ }^{1}$ \\ Sandra Vidal Nogueira ${ }^{2}$
}

Resumo: Os estudos sobre a educação inclusiva são práticas curriculares de inclusão de talento, deficiência, origem socioeconômica ou cultural em escolas e salas de aula provedoras, em que as necessidades desses alunos sejam satisfeitas. Nessa perspectiva, tendo por base a revisão de literatura sobre o tema, o presente artigo objetiva explicitar algumas das aproximações entre Teoria Crítica de currículo e Educação Inclusiva a partir do detalhamento de quatro subitens: a problemática curricular e o traçado de seu campo conceitual; a inserção da teoria crítica de currículo, a partir dos anos 80; a década de 90 e a institucionalização de práticas pedagógicas inclusivas; os marcos legais para a promoção da educação inclusiva no Brasil.

Palavras-chave: Currículo; Educação inclusiva; Educação científica.

\section{REFERENCE LANDMARKS OF APPROXIMATIONS BETWEEN CRITICAL CURRICULUM THEORY AND INCLUSIVE EDUCATION}

\begin{abstract}
Inclusive education studies are curricular practices for the inclusion of talent, disability, socioeconomic or cultural background in provider schools and classrooms, where the needs of these students are met. From this perspective, based on the literature review on the subject, this article aims to explain some of the approaches between Critical Curriculum Theory and Inclusive Education from the detailing of four sub-items: the curricular problematic and the outline of its conceptual field; the insertion of critical curriculum theory from the 1980s onwards; the 1990s and the institutionalization of inclusive pedagogical practices; the legal frameworks for promoting inclusive education in Brazil.
\end{abstract}

Keywords: Curriculum; Inclusive education; Science education.

\section{MERCADOS DE REFERENCIA PARA ENFOQUES ENTRE TEORÍA CRÍTICA DEL CURRÍCULO Y LA EDUCACIÓN INCLUSIVA}

Resumen: Los estudios sobre educación inclusiva son prácticas curriculares para la inclusión del talento, la discapacidad, el origen socioeconómico o cultural en las escuelas y dotaciones de aulas, en las que se satisfagan las necesidades de estos estudiantes. En esta perspectiva, a partir de la revisión de la literatura sobre el tema, este artículo tiene como objetivo explicar algunos de los enfoques entre la Teoría Crítica del Currículo y la Educación Inclusiva a partir del detalle de cuatro subtemas: la problemática curricular y el esbozo de su campo conceptual; la inserción de la teoría crítica del curriculum, a partir de la década de los ochenta; los noventa y la institucionalización de prácticas pedagógicas inclusivas; los marcos legales para promover la educación inclusiva en Brasil.

Palabras llave: Currículum; Educación inclusiva; Enseñanza de las ciencias.

\footnotetext{
${ }^{1}$ Doutora em Educação (PUCRS). Mestre em Educação nas Ciências (Unijui). Professora e Pesquisadora na Universidade Federal da Fronteira Sul /campus Cerro Largo/RS.

${ }^{2}$ Pós-Doutoranda em Direito (Universidade Regional Integrada do Alto Uruguai e Missões-URI, Campus Santo Ângelo, RS), Doutorado em Educação (PUCSP). Professora e Pesquisadora na Universidade Federal da Fronteira Sul (UFFS), vinculada ao Programa de Mestrado em Desenvolvimento e Políticas Públicas, Campus de Cerro Largo, RS.
} 


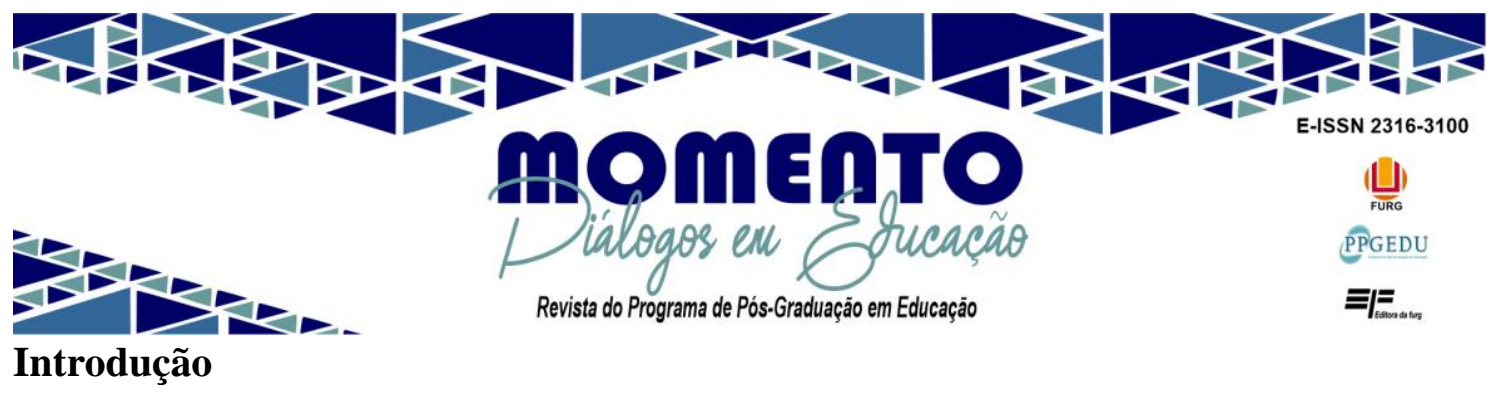

Desde a promulgação da Constituição de 1988, observa-se, no Brasil, que o ambiente escolar tem sido alterado, substancialmente, pela criação de um sistema educacional inclusivo. Houve grande empenho de governos e redes de ensino em criar oportunidades de acesso à escola, fazendo dos espaços de escolarização regular, lugares para todos, sem exceções.

Buscam-se novações para as salas de aula, com a implementação de práticas pedagógicas diferenciadas. A intenção é deixar de lado velhos hábitos, que acabam por reforçar barreiras e dificultar a aprendizagem de estudantes. Apesar de todo o esforço concentrado nessa direção, as comunidades escolares e alguns de seus protagonistas equipes diretivas, professores e famílias sentem a necessidade de consolidar os processos de educação inclusiva.

Desse ponto de vista, os estudos sobre a educação inclusiva, mais especificamente a escolarização de pessoas com Necessidades Educacionais Especiais (NEE) - estudantes com deficiência intelectual, auditiva, visual, física e deficiência múltipla, transtornos globais do desenvolvimento e altas habilidades/superdotação, podem ser considerados indispensáveis para a alteração das concepções e estratégias pedagógicas na cultura escolar brasileira.

A educação inclusiva pode ser definida, desse modo, como prática curricular destinada à inclusão de todos. Nessa perspectiva, tendo por base a realização de um estudo bibliográfico, de revisão de literatura sobre o tema, o presente artigo objetiva explicitar algumas das aproximações entre Teoria Crítica de Currículo e Educação Inclusiva, considerando os espaços de educação escolarizada importantes instrumentos de reprodução das desigualdades, propriamente constituídos.

Os pensamentos de Apple (1982; 1989), Bersntein (1996), Fourquin (1993) e Sacristán (1995) sobre as questões atinentes aos currículos críticos e plurais são as referências de base para tratar das matrizes curriculares inclusivas, organizados em quatro subitens. São eles: a) a problemática curricular e o traçado de seu campo conceitual; b) a inserção da teoria crítica de currículo a partir dos anos 80; c) a década de 90 e a institucionalização de práticas pedagógicas inclusivas; e, alguns marcos legais, para a promoção da educação inclusiva no Brasil. 


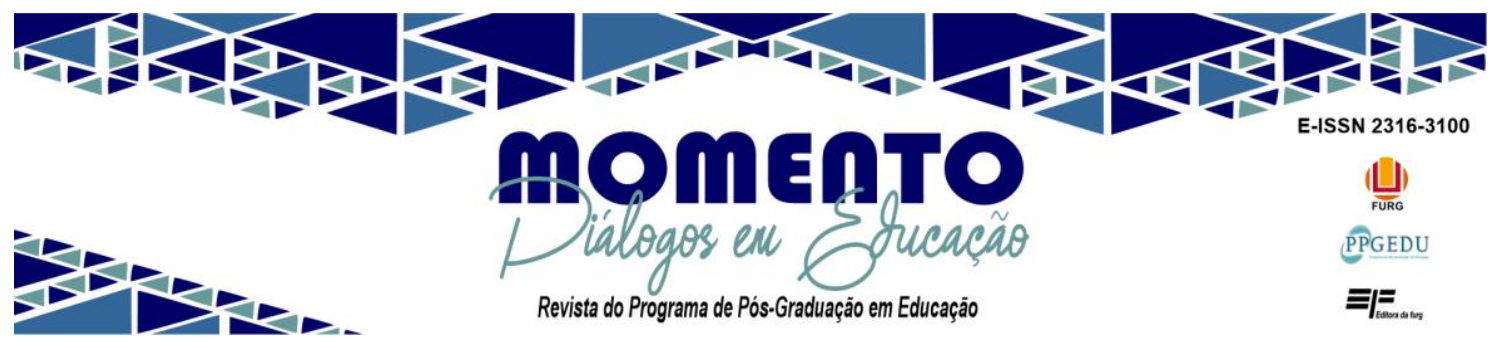

A problemática curricular e o traçado de seu campo conceitual

Os estudos sobre a temática do currículo, a partir dos anos 40 (do século passado), focalizaram o predomínio de preocupações com sua natureza prescritiva do mesmo. Esta matriz teórica de análise e interpretação mais clássica, digamos assim, predominou até os anos 80, no Brasil, e com forte influência teórica norte-americana. Um bom exemplo é expresso pela referência no pensamento de Tyler (1974). Segundo Silva (1999, p. 24), embora admita "a filosofia e a sociologia como possíveis fontes de objetivos para o currículo, o paradigma formulado por Tyler centra-se em questões de organização e desenvolvimento".

Após a promulgação da Constituição de 1998, emergiram os debates sobre o sentido democrático das políticas públicas em Educação no Brasil e a necessidade de superação desse paradigma. (BRASIL, 1988). Desde então, o desafio posto tem sido buscar respostas relativas ao que, ao como e ao para que ensinar e, diante dos questionamentos que emergem, a temática currículo passou a assumir centralidade na condição de importante ferramenta conceitual para o avanço da democracia brasileira.

Apesar disso, o entendimento sobre as prioridades dos currículos escolares tem gerado grande polêmica, afinal, se constitui em produto histórico e em prática social, culturalmente construída. As divergências residem nas formas assumidas pela produção do conhecimento escolar e as formas pelas quais acontecem as relações de poder no interior e no entorno dos processos de ensino e aprendizagem (APPLE, 1982;1989).

Nesse sentido, Forquin (1993) enfatiza que a denominação currículo possui sentidos variados, em termos de riqueza semântica e de usos, no vocabulário pedagógico inglês e francês, do qual se origina. No léxico francês, o termo é restrito à categoria específica de objetos pertencentes à esfera educativa, equivalendo à ideia de programas educativos. Já nos países de língua inglesa, é delimitado pelas noções de prescrição/execução e currículo oculto/contextos culturais, com uma conotação mais integrativa ao termo.

Distinções à parte, a conceituação de currículo trata, basicamente, da dele como ação humana, ou seja, realizada com uma atividade que chancela conhecimentos socialmente válidos e legitima práticas discursivas, produtoras de certo tipo de 


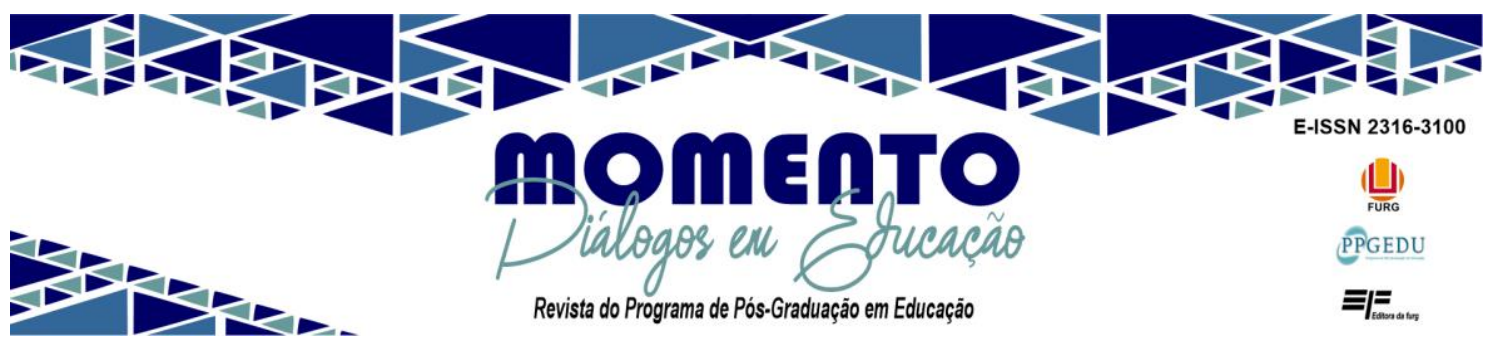

identidades e subjetividades. A esse respeito, de acordo com Silva e Moreira (1995, p. 86), vale a pena ressaltar que:

Currículo não é a agora a declaração de áreas e temas - seja ela feita pela administração ou pelos professores -, mas a soma de todo tipo de aprendizagens e de ausências que os alunos obtêm como consequência de estarem escolarizados.

Está inserida, nessa orientação conceitual, a compreensão de que pensar e fazer currículo é, antes de mais nada, uma ação no âmbito da produção dos saberes e da ordenação das coisas humanas ou a elas relacionadas (exercício de poder). O que importa é a forma segundo a qual o conhecimento é produzido, ordenado e apropriado, dentro e no extramuros da escola. Em decorrência desse entendimento, coloca-se a tarefa de desvelar os múltiplos sentidos da lógica disciplinar nas práticas curriculares.

A palavra disciplina apresenta um duplo sentido: tanto induz à delimitação de um campo específico como à hierarquização e ao exercício do poder. (...) O processo de disciplinarização pelo qual passa a construção da ciência moderna traz embutida em si esta afirmação da equivalência entre saber e poder. (...) Por detrás dela [disciplinarização], paira o controle: compartimentalizando, fragmentando, é muito mais fácil controlar-se o acesso, o domínio que os alunos terão e também controlar-se o que eles sabem. (Gallo, 1997, p. 117-118).

Segundo Bernstein (1996), a revisita, na noção de lógica disciplinar, direciona o leitor para a busca de alternativas pedagógicas que viabilizem superar a desarticulação dos conteúdos e sua consequente fragmentação. O resultado negativo mais notório da adoção por esse modelo. Isto significa dizer: não basta repetir! É preciso dar outros sentidos aos processos de ensino e aprendizagem, de modo a possibilitar articulações educativas: curriculares e sociais a partir das várias dimensões da existência humana.

Dentre as questões que surgem com essa tomada de posição, estão aquelas relacionadas à preservação dos valores universais e ao direito às diferenças. Por essa razão, há um crescente interesse pelo sentido democrático das escolhas curriculares mais inclusivas, expresso em propostas de educação com desenho e contornos de pluralidade cidadã. De acordo com Sacristán (1995, p. 91) 


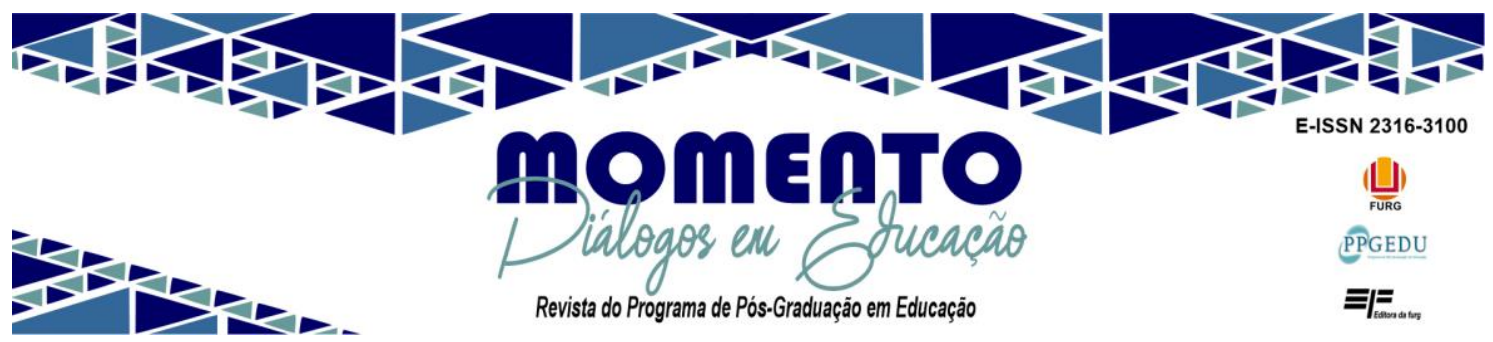

A educação multicultural pode ser instrumentalizada a partir de uma cultura dominante para assimilar uma cultura minoritária em condições desiguais e com oportunidades menores no sistema social e educacional; emprega-se como instrumento para reduzir os preconceitos de uma sociedade para com minorias étnicas; pode-se formulá-la como programas diferenciados para que diversos setores culturais de uma sociedade encontrem ambientes educativos apropriados a cada um: pode-se entendê-la como uma visão não etnocêntrica da cultura que acolha o pluralismo cultural sob qualquer faceta.

Inserida, portanto, no campo de estudos da teoria crítica de currículo, este tipo de visão sobre a educação sinaliza para algumas urgências pedagógicas. São elas: a) a ampliação conceitual dos debates curriculares; b) a compreensão de que o currículo é um campo de articulação entre os saberes, as culturas e os poderes, assim como de formação humana moral e ética; d) a superação das dicotomias clássicas (pensar/fazer; global/local; universal/específico) na esfera das práticas educacionais e fora dela.

\section{A inserção da teoria crítica de currículo a partir dos anos 80}

A década de 80 foi um período marcado por mudanças profundas na produção da vida material, simbólica e sociocultural brasileira. Constata-se, de modo crescente, o surgimento de tecnologias ativas, interativas e mecanismos multirreferenciais para garantir a defesa da liberdade subjetiva, na perspectiva da obtenção de requisitos fundamentais ao pleno desenvolvimento na sociedade contemporânea. Este cenário tem exigido um novo entendimento sobre as finalidades da educação e as funções dos currículos escolares.

Considerando a construção curricular, sob a ótica de núcleo principal do processo educacional institucionalizado, ela se torna expressão marcante dos elos existentes entre escolarização e práticas sociais. Vale lembrar que, no interior das dinâmicas curriculares, ocorrem procedimentos de seleção, organização, apropriação e distribuição dos conhecimentos socialmente válidos. Nesse sentido, Silva (1995, p. 20) enfatiza “(...) que as identidades hegemônicas constituídas pelos regimes atuais de representação podem ser desestabilizadas e implodidas". 


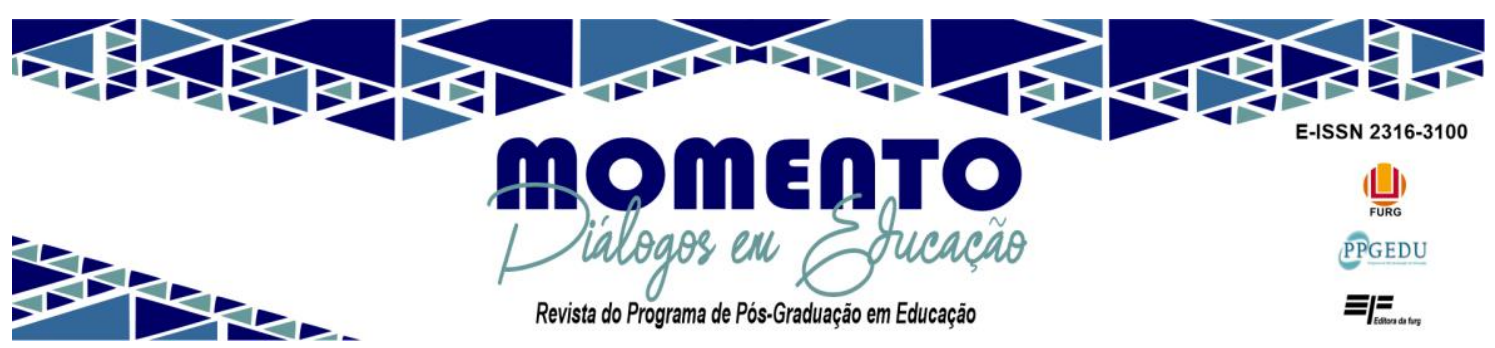

Busca-se, assim, uma tomada de consciência civilizatória pautada na ética da diversidade. Os princípios norteadores desse movimento podem ser assim relacionados, de acordo com D’Ambrósio (1995, p. 38), preconizando o "respeito ao outro com todas as suas diferenças; solidariedade como o outro na satisfação de suas necessidades de sobrevivência e de transcendência; busca, com o outro, de convivência harmoniosa com a natureza."

No paradigma clássico, valia a performance de pessoas competentes, eficientes e eficazes. A partir da teoria crítica de currículo, se vislumbra uma noção mais orgânica e integral da pessoa humana, com ênfase na formação humana. Há, pois, o reconhecimento da pluralidade de visões de mundo, culturas, sociabilidades, espiritualidades e modelos de desenvolvimento humano.

Contrariamente ao discurso unitário da globalização econômica, coloca-se o desafio da diversidade, bem como da criação de espaços mais democráticos. Há de se ter inspiração para colocar em relevo a cultura do cuidado, da sensibilidade, do afeto, do reconhecimento e da aceitação ativa. Momento de respeitar o diferente, sem querê-lo uniforme e acolher o diverso, sem forçá-lo à unicidade, compreendendo que a complexidade e a multiplicidade são o que torna rica a vida humana, dando-lhe sentido e razão de ser.

Todo esse entendimento encontra-se em oposição à lógica unidimensional, e há o reconhecimento, igualmente, de que mudanças, de cunho paradigmático, não se efetivam no curto prazo. Muito já se fez nas últimas décadas, mas ainda há um longo percurso para alterar o conceito de que o indivíduo/aluno é tão só um ser racional, adotando uma visão que o perceba em suas múltiplas dimensões: alguém que pensa e sente, provoca e reage, faz e desfaz, aprende, desaprende e volta a aprender. Nesse contexto, defende-se a ideia de uma visão paradigmática que dê relevo à questão para a institucionalização das práticas pedagógicas inclusivas, cenário que será descrito a seguir.

\section{A década de 90 e a institucionalização de práticas pedagógicas inclusivas}

A década de 90 foi decisiva na delimitação dos cenários políticos e sociais de combate e superação da exclusão em suas mais variadas formas e manifestações. Um dos 


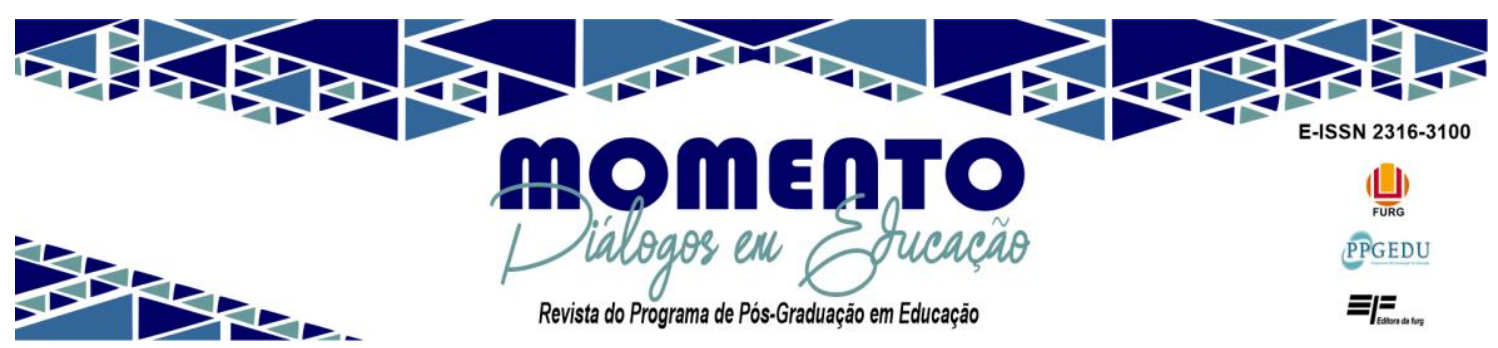

horizontes de possibilidades que se vislumbrava e, ainda, permanece forte nas lutas sociais desencadeadas, desde então, é aquele direcionado ao campo de disputas sobre o direito à educação. Este importante período histórico representa um marco estratégico no papel que a educação passou a desempenhar.

Alguns eventos merecem destaque em face da promoção de uma educação que visualize a construção do conhecimento individual (porque cada um aprende com um 'tempo/ritmo diferenciado') e coletivo (porque nas trocas de conhecimento nos empoderamos). O papel do Estado, na formação dos mesmos, é indispensável, também, para que acordos e declarações sejam efetivados no sentido de garantir educação igualitária para todos, respeitando as suas necessidades e ritmos de aprendizagem. Nessa linha de pensamento, as três Conferências Mundiais de Educação para Todos, entre os anos de 1993 e 2000, são marcos em que a Educação passou a desempenhar ou efetivar a inclusão em um âmbito mundial. Na primeira delas, no ano de 1990, em Jomtien, na Tailândia, foi elaborada a Declaração de Jomtien (UNESCO, 1990). Em Nova Delhi, na Índia, no ano de 1993, foi produzida a Declaração de Nova Delhi (BRASIL, 1993) e, em Dakar, no Senegal, no ano de 2000, o Marco de Ação de Dakar (BRASIL, 2000).

A partir dessas Conferências, a perspectiva da educação inclusiva começou a ganhar expressão qualificada, emergindo o movimento mundial pela Educação para Todos, ou seja, a defesa da ideia da democratização dos processos e dos direitos de igualdade para todas as pessoas, como premissa básica ao desenvolvimento humano e social, independentemente de suas condições socioculturais, históricas, econômicas, físicas, psíquicas ou quaisquer outras características individuais (BRASIL, 1994b). O Brasil, por sua vez, como país signatário deste documento, assumiu o compromisso de erradicar o analfabetismo e universalizar o ensino fundamental.

Desencadeia-se, assim, um amplo debate para fins de elevar a consciência do poder público e da sociedade civil para a importância da educação como direito subjetivo de todas as pessoas e como condição básica ao exercício da cidadania ativa, visando à construção de cenários sociais pautados pela justiça e pela equidade.

A Conferência Mundial sobre Necessidades Educativas Especiais: Acesso e Qualidade, em Salamanca, na Espanha. Nesta Conferência, foi produzida a Declaração de Salamanca (BRASIL, 1994a), cujo foco esteve voltado para estudantes que têm 


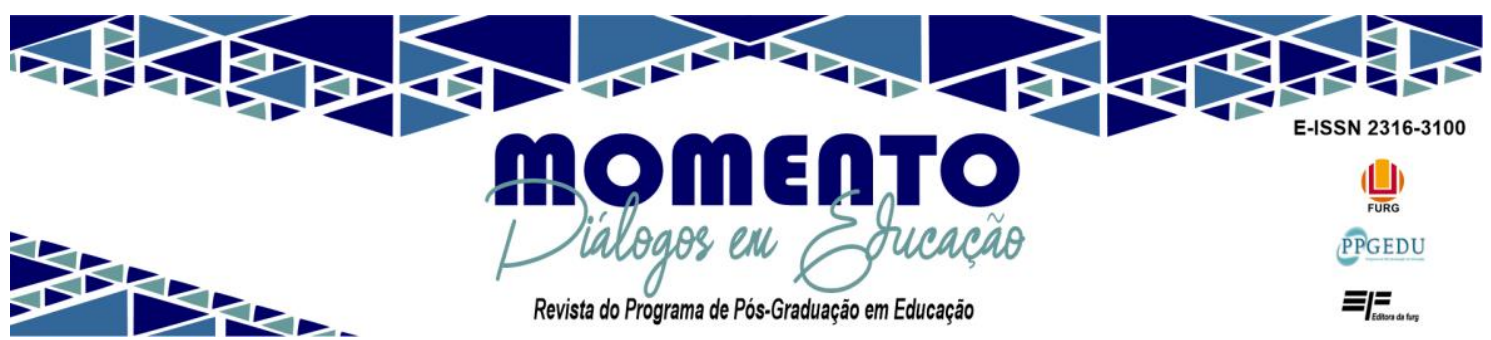

necessidades educativas especiais e para as políticas de justiça social. Além disso, a expressão Educação Especial foi substituída por educação inclusiva, ampliando o conceito.

Todas as escolas deveriam acomodar todas as crianças independentemente de suas condições físicas, intelectuais, sociais, emocionais, linguísticas ou outras. Devem incluir crianças deficientes ou superdotadas, crianças de rua e que trabalham crianças de origem remota ou de população nômade, crianças pertencentes a minorias linguísticas étnicas ou culturais e crianças de outros grupos em desvantagem ou marginalizados (BRASIL, 1994, p. 331)

Constata-se, assim, um reforço aos deveres de Estado como garantir das condições de acesso, permanência e aproveitamento no contexto escolar. Se, por um lado, o panorama político mundial sinalizou, desde então, na direção de avanços necessários no binômio inclusão/exclusão; por outro, o marco histórico legal apontou uma série de dispositivos que, aos poucos, foram sendo criados e vieram ao encontro de garantir maior consistência normativa para os ideais pretendidos (UNESCO, 1993; BRASIL, 2000; MANTOAN, 2008).

\section{Alguns marcos legais para a promoção da educação inclusiva no Brasil}

A Constituição de 1988, em seu art. 208 (BRASIL, 1988), já sinalizava para a implementação da educação inclusiva, pois a mesma sinaliza que "o dever do Estado com a Educação "o dever do Estado com a educação será efetivado mediante a garantia de atendimento educacional especializado aos portadores de deficiência, preferencialmente na rede regular de ensino". Desde então, o Brasil tem firmado compromissos referentes à proteção e aos mecanismos que assegurem o exercício pleno e equitativo de todos os direitos humanos e as liberdades fundamentais das pessoas com deficiência. A inclusão escolar representa um movimento social mais amplo. Significa a defesa pela justiça social na equiparação de oportunidades e pelo reconhecimento político das diferenças. Apesar disso, a existência de tensionamentos em relação à efetivação dos direitos para as diferentes populações não é garantia de preservação das conquistas sociais.

Educação escolar e desenvolvimento humano, cada vez mais, se aproximam, ou 


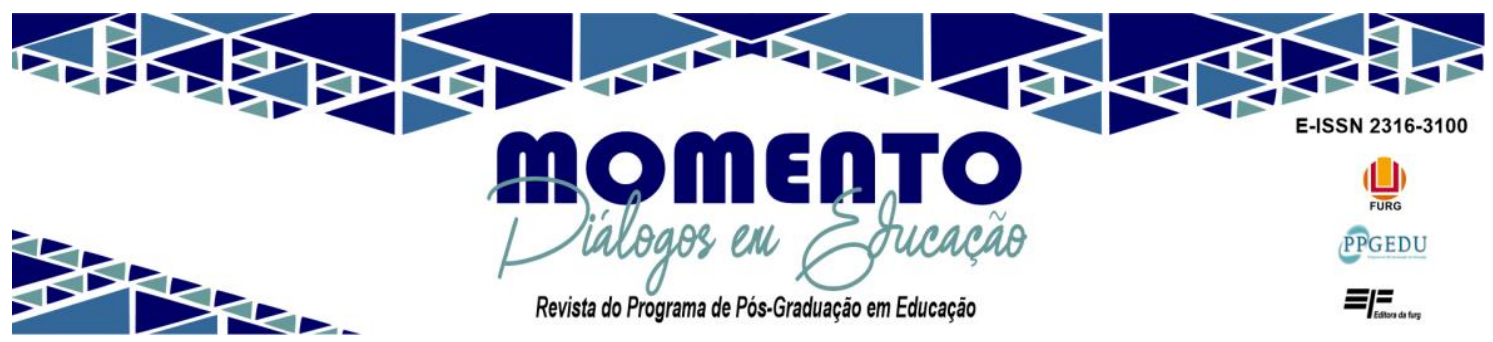

seja, torna-se prioritário, construir novas mentalidades para responder aos principais desafios do processo de redemocratização no país. São eles: a construção de um modelo de desenvolvimento sustentável, a necessidade de ampliação dos mecanismos de participação e a premência da redução das desigualdades econômicas, sociais e culturais.

Nesse sentido, houve a edição de inúmeras normativas relacionadas à matéria. Destacam-se, a seguir, o conjunto dos principais instrumentos, compreendidos entre os anos de 1989 e $2015^{3}$, que tratam da relação existente entre planejamento curricular e prática social.

a) Lei $n^{0} 7.853$, de 24 de outubro de 1989 , dispõe sobre o apoio às pessoas portadoras de deficiência, sua integração social, sobre a Coordenadoria Nacional para Integração da Pessoa Portadora de Deficiência (Corde) e institui a tutela jurisdicional de interesses coletivos ou difusos dessas pessoas, disciplina a atuação do Ministério Público, define crimes e dá outras providências (BRASIL, 1989).

b) Lei $n^{\circ} 8.069$, de 13 de julho de 1990, prevê o Estatuto da Criança e do Adolescente, no qual se dispõe que a criança e o adolescente portadores de deficiência deverão receber atendimento educacional especializado, preferencialmente, na rede regular de ensino (BRASIL, 1990).

c) Lei $n^{\circ}$ 9.394, 20 de dezembro de 1996 - Lei de Diretrizes e Bases da Educação Nacional, em seu Capítulo V, da atenção à Educação Especial, no artigo 58, ficou estabelecido que a educação de alunos com necessidades especiais deve ser conduzida, preferencialmente, na rede escolar regular de ensino (BRASIL, 1996).

d) Decreto n 3.298, de 1999, regulamenta a Lei no 7.853, de 24 de outubro de 1989, e dispõe sobre a Política Nacional para a Integração da Pessoa Portadora de Deficiência, consolida as normas de proteção e dá outras providências. (BRASIL, 1999).

e) Lei n ${ }^{\circ}$ 10.172, de 9 de janeiro de 2001, aprova o Plano Nacional de Educação e estabelece vinte e oito objetivos e metas para a educação das pessoas com necessidades educacionais especiais (BRASIL, 2001a).

f) Resolução $\mathrm{n}^{\circ}$ 2, de 11 de setembro de 2001, institui Diretrizes Nacionais para a

\footnotetext{
${ }^{3}$ Fez-se a opção por este recorte temporal, considerando os marcos regulatórios de criação/consolidação da educação inclusiva que reorientaram os referenciais curriculares nos diferentes níveis dos sistemas de ensino no Brasil, com base nos pressupostos das matrizes das teorias críticas.
} 


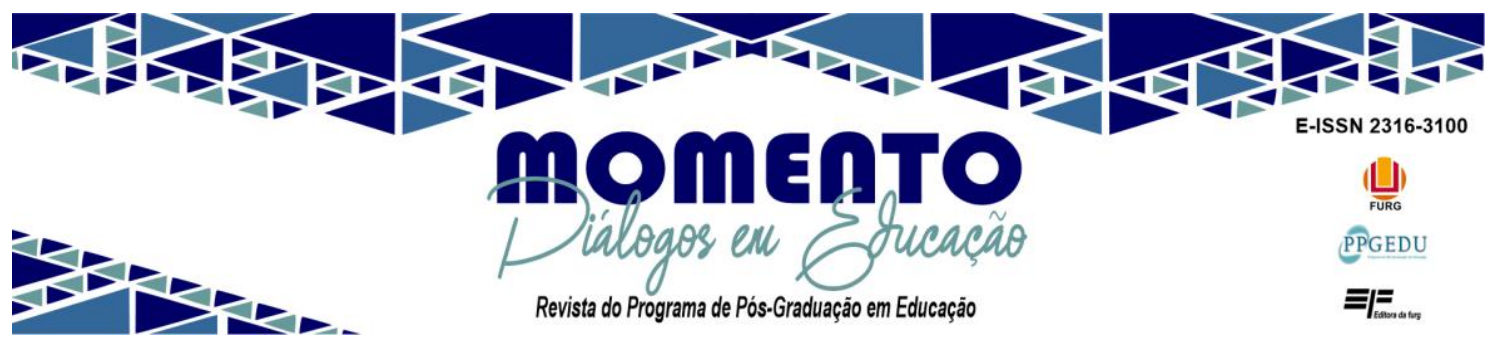

Educação Especial na Educação Básica (BRASIL, 2001b).

g) Decreto $n^{\circ} 3.956$, de 8 de outubro de 2001, trata da eliminação de todas as formas de discriminação contra as pessoas portadoras de deficiência, em atendimento à Convenção da Guatemala (BRASIL, 2001c).

h) Resolução no 1/2002 do Conselho Nacional de Educação (CNE), de 19 de fevereiro de 2002, definindo que as universidades devem prever em sua organização curricular formação de professores voltada para a atenção à diversidade e que contemple conhecimentos sobre as especificidades dos alunos com necessidades educacionais especiais (BRASIL, 2002a).

i) Lei $\mathrm{n}^{\mathrm{o}}$ 10.436, de 24 de abril de 2002, prevê a Língua Brasileira de Sinais (LIBRAS), como meio legal de comunicação e expressão de comunidade de pessoas surdas (BRASIL, 2002b).

j) Lei $n^{\circ} 10.845$, de 5 de março de 2004, institui o Programa de Complementação ao Atendimento Educacional Especializado às Pessoas Portadoras de Deficiência (PAED) (BRASIL, 2004).

k) Decreto $\mathrm{n}^{\circ}$ 5.626, de 22 de dezembro de 2005, dispõe sobre a inclusão de LIBRAS como componente curricular e sobre a formação e a certificação de professor, instrutor e tradutor/intérprete desse novo meio legal de comunicação e expressão (BRASIL, 2005).

1) Decreto $\mathrm{n}^{\mathrm{o}}$ 6.571, de 17 de setembro de 2008, dispõe sobre o atendimento educacional especializado (BRASIL, 2007).

m) Decreto $\mathrm{n}^{\mathrm{o}}$ 6949, de 25 de agosto de 2009, promulga a Convenção Internacional sobre os Direitos das Pessoas com Deficiência e seu protocolo facultativo, assinados em Nova York, em 30 de março de 2007 (BRASIL, 2009).

n) Lei $n^{\circ} 13.005$, de 25 de junho de 2014, aprova o Plano Nacional de Educação de Educação (PNE) para o período de 2014-2024, garantindo o atendimento das necessidades específicas na educação especial e assegurando o sistema educacional inclusivo em todos os níveis, etapas e modalidades de ensino (BRASIL, 2014).

o) Lei $n^{\text {o }} 13.146$, de 6 de julho de 2015, conhecida como Lei da Inclusão que institui a Lei Brasileira de Inclusão da Pessoa com Deficiência (Estatuto da Pessoa com Deficiência) destinada a assegurar e a promover, em condições de igualdade, o exercício 


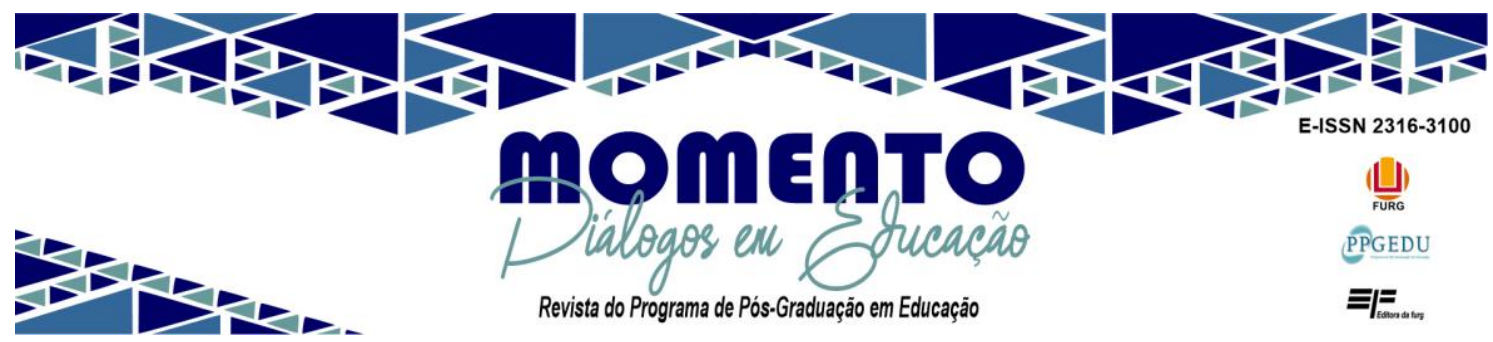

dos direitos e das liberdades fundamentais por pessoa com deficiência, visando à sua inclusão social e cidadania. (BRASIL, 2015).

Há de se considerar, porém, que, somente em 2007, é elaborada a Política Nacional de Educação Especial na Perspectiva da Educação Inclusiva (BRASIL, 2008), por meio da qual o/a estudante que tem necessidades educativas especiais é visto como uma pessoa que possui infinitas possibilidades e que precisa de atendimento especializado para efetivar suas potencialidades. Sobre a questão conceitual, propriamente dita, Real alerta (BRASIL, 2014, p. 5376) que:

a forma na qual a expressão "necessidades educacionais especiais" (NEE) aparece na LDB (1996) resulta em graves erros de interpretação vivenciados no âmbito escolar. Numa primeira análise do texto da referida lei, ao compreender o conceito de educandos com necessidades especiais como está posto na Declaração de Salamanca (1994), a abrangência dos alunos atendidos pela educação especial é ampliada, visto que esta Declaração considera tal alunado como todo aquele que apresenta dificuldades em seu processo de escolarização. Já numa outra vertente, se o conceito de necessidades especiais for restrito apenas ao exposto no texto da LDB (1996), desvinculado da Declaração de Salamanca (1994), pode-se concluir que apenas os alunos portadores de alguma deficiência apresentariam, de fato, necessidades educacionais especiais. Tal indefinição parece ter fim com a publicação do volume sobre Adaptações Curriculares, dos Parâmetros Curriculares Nacionais (BRASIL, 1998), que comunga com o que é proposto pela Declaração de Salamanca (BRASI, 1994).

Os sentidos do uso do termo educação inclusiva foram se ajustando aos diferentes contextos históricos no Brasil e, na atualidade, o conceito de inclusão refere-se ao reconhecimento do outro, estar junto e interagir. Nesse sentido, Viegas (2012) e Beyer (2013) entendem que a inclusão é um movimento educacional, social e político. Parte-se do pressuposto de que todas as pessoas são diferentes e podem frequentar o mesmo espaço, no caso da educação escolar, a sala de aula. A perspectiva de educação inclusiva contempla as demandas do estudante com deficiência física, daquele com comprometimento mental, ou, até mesmo, do superdotado. Atende às múltiplas realidades, independentemente de sua condição física, cognitiva, emocional, cultural ou social. Nesse sentido, Xavier (2002, p. 19) considera que: 


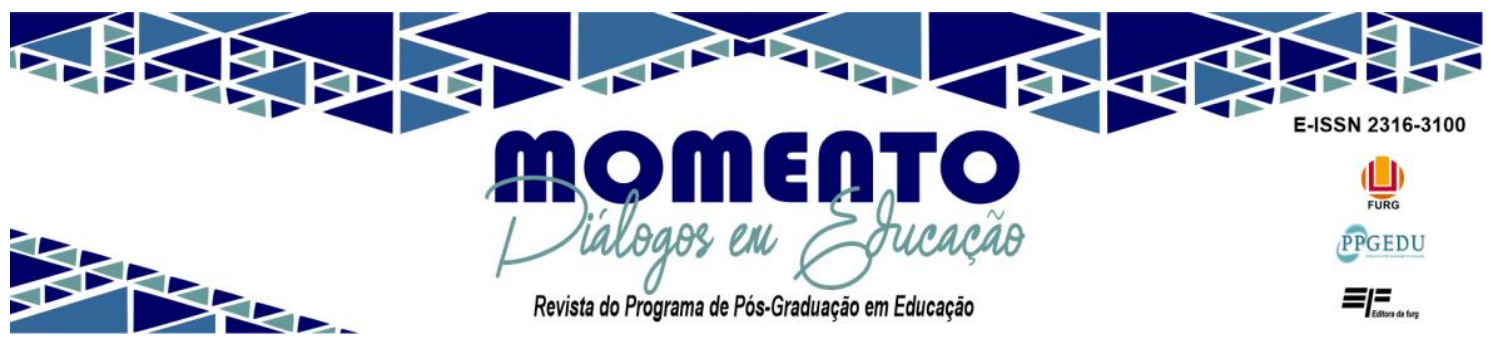

[...] a construção da competência do professor para responder com qualidade às necessidades educacionais especiais de seus alunos em uma escola inclusiva, pela mediação da ética, responde à necessidade social e histórica de superação das práticas pedagógicas que discriminam, segregam e excluem, e, ao mesmo tempo, configuram, na ação educativa, o vetor de transformação social para a equidade, a solidariedade, a cidadania.

Apesar disso, pode-se afirmar que as práticas de inclusão escolar, no Brasil, avançam de maneira lenta. A fase de conscientização sobre sua importância ainda é recorrente. Ignora, por exemplo, o que acontece ao redor, e a marginalização das diferenças ainda são duras realidades do espaço escolar.

A inclusão escolar é, certamente, um movimento inovador e, como tal, remete às possibilidades de modernização e reestruturação das estruturas e dinâmicas escolares. A esse respeito, de acordo com Mantoan (2003, p. 33):

Mudar a escola é enfrentar muitas frentes de trabalho, cujas tarefas fundamentais são: Recriar o modelo educativo escolar, tendo como eixo o ensino para todos, reorganizar pedagogicamente as escolas, abrindo espaços para que a cooperação, o diálogo, a solidariedade, a criatividade e o espírito crítico sejam exercitados nas escolas, por professores, administradores, funcionários e alunos, porque são habilidades mínimas para o exercício da verdadeira cidadania, garantir aos alunos tempo e liberdade para aprender, bem como um ensino que não segrega e que reprova a repetência, formar, aprimorar continuamente e valorizar o professor, para que tenha condições e estímulo para ensinar a turma toda, sem exclusões e exceções.

Paetzold e Nogueira (2016), prosseguindo os debates sobre os sentidos pedagógicos da inclusão, reforçando a ideia de que a exclusão escolar está cada vez mais evidente, em suas mais diversas e perversas formas e essas práticas, precisam ser combatidas e superadas. $\mathrm{Na}$ realidade, o que acontece é que a escola se configura como um espaço propício para desenvolver processos de subjetivação, uma vez que, nela, não se aprende somente os conteúdos escolares, mas, sobretudo, formas de ser e estar no mundo.

\section{Considerações finais}

Os movimentos voltados para a construção de um sistema educacional brasileiro inclusivo ainda se mostram inconclusos na realidade educacional brasileira. Apesar do Brasil ter alcançado patamares significativos no fortalecimento da perspectiva inclusiva 


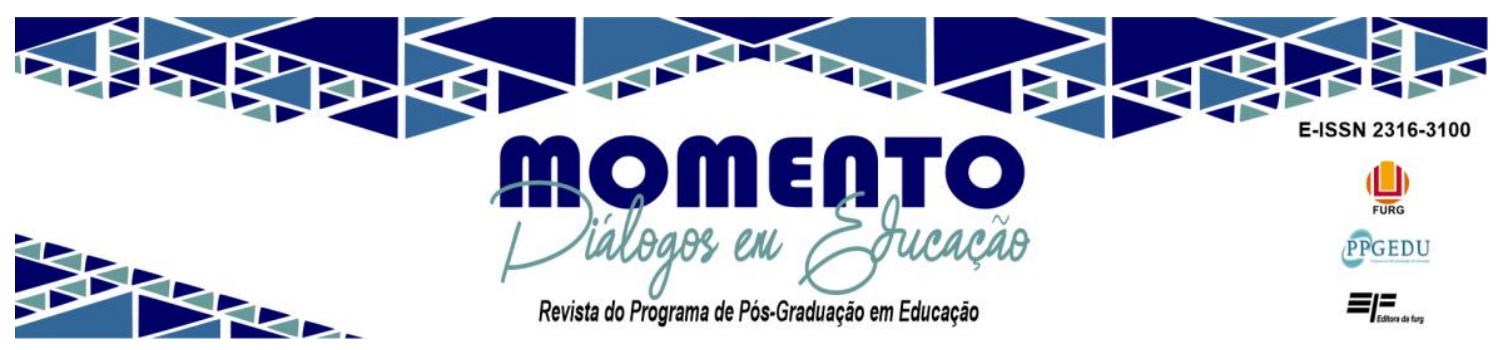

como eixo organizador das políticas educacionais, os avanços nas práticas de inclusão escolar necessitam pautar a acessibilidade à inclusão escolar como central para a garantia dos direitos fundamentais e da promoção ao respeito pela dignidade da pessoa humana.

Houve um significativo aumento na difusão de dispositivos formativos, pedagógicos, políticos e sociais no interior dos sistemas de ensino público e privado, no que diz respeito ao uso de conceitos, abordagens teóricas, métodos, técnicas e metodologias mais críticas, dialógicas e interdisciplinares. Iniciaram-se, assim, movimentos progressivos de mudança cultural nos modos de pensar e fazer os currículos escolares. Contudo, existem, ainda, inúmeras barreiras de consolidação dos processos educativos, circunscritas aos ambientes do ensino e da aprendizagem em relação à própria aceitação sobre a educação inclusiva e seu maior pertencimento aos universos curriculares de escolarização de crianças, jovens e adultos.

Pensando sobre a produção científica brasileira, nas aproximações existentes entre as teorias críticas de currículo e o ideário da educação inclusiva, os desafios apontam na direção da reorganização dos tempos pedagógicos, considerando redefinições temáticas, seleção de conteúdos prioritários, narrativas de empoderamento no trabalho didático e metodologias de ensino com foco na pluralidade de visões de mundo. São trabalhos que objetivam atender à escolarização de pessoas com Necessidades Educacionais Especiais (NEE) - estudantes com deficiência intelectual, física e deficiência múltipla, transtornos globais do desenvolvimento e altas habilidades/superdotação em ambientes escolares.

Desse ponto de vista, há de se ter clareza de que o investimento na formação profissional mostra-se como uma urgência histórica. Isso implicar definição de diretrizes para a formação profissional na educação especial e sua capilaridade na qualificação dos processos de escolarização.

Não se pode esquecer que o preconceito é aprendido! O pensamento excludente que se mantém vivo é fruto de uma visão determinista e restritiva, que ignora, muitas vezes, tudo aquilo que é diferente e que produz diferenças. As marcas da exclusão e segregação, na história educacional brasileira, são de difícil tratamento. Há todo um esforço institucional, após a Constituição de 1998, objetivando maior integração da perspectiva cidadã no universo dos processos educacionais, sejam eles familiares, sejam escolares. 


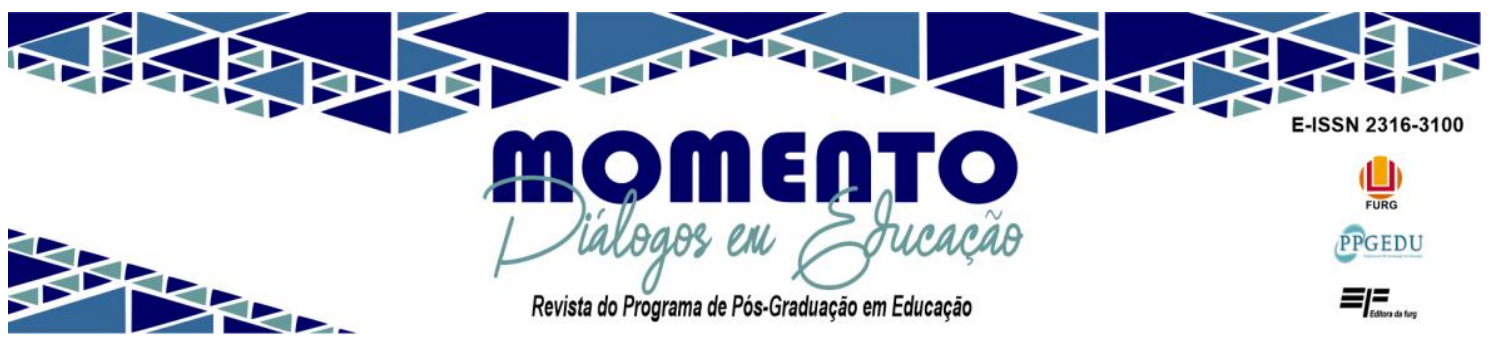

Há consenso, portanto, de que é preciso romper com velhos tabus, questionar o que discrimina e coloca à parte pessoas, escolas, instituições e programas e, assim, compreender como esses mecanismos de inclusão/exclusão se caracterizam como elementos essenciais para que as práticas inclusivas tenham lugar e possam acontecer efetivamente. Enfim, as limitações e singularidades de cada pessoa precisam ser entendidas, valorizadas e respeitadas!

\section{Referências}

APPLE, M. Educação e poder. Trad. M. C. Monteiro. Porto Alegre: Artes Médicas, 1989.

APPLE, M. Ideologia e currículo. São Paulo: Brasiliense, 1982.

BERSNTEIN, B. A estruturação do discurso pedagógico: classe, códigos e controle. Petrópolis: Vozes, 1996.

BEYER, H. O. Inclusão e avaliação na escola. Porto Alegre: Mediação, 2013.

BRASIL. Constituição da República Federativa do Brasil. Brasília: Senado Federal, 1988.

Disponível

em:

http://www.planalto.gov.br/ccivil_03/Constituicao/Constituicao.htm. Acesso em: 03 ago. 2020.

BRASIL. Declaração de Nova Delhi sobre Educação Para Todos. Nova Delhi/Índia: Unesco, $1993 . \quad$ Disponível em: http://unesdoc.unesco.org/images/0013/001393/139393por.pdf. Acesso em: 03 ago. 2020.

BRASIL. Declaração de Salamanca. Brasília: MEC/SEESP, 1994a. Disponível em: http://portal.mec.gov.br/seesp/arquivos/pdf/salamanca.pdf. Acesso em: 03 ago. 2020.

BRASIL. Decreto n' 3.298, de 20 de dezembro de 1999, regulamenta a Lei $n^{\circ} 7.853$, de 24 de outubro de 1989, que dispõe sobre a Política Nacional para a Integração da Pessoa Portadora de Deficiência, consolida as normas de proteção, e dá outras providências. Brasília, 1999. Disponível em: http://www.planalto.gov.br/ccivil_03/decreto/d3298.htm. Acesso em: 05 out. 2020.

BRASIL. Decreto $\mathbf{n}^{\mathbf{0}}$ 3.956, de 8 de outubro de 2001, que promulga a Convenção Interamericana para a Eliminação de Todas as Formas de Discriminação contra as Pessoas Portadoras de Deficiência. Brasília: Senado Federal 2001c. Disponível em: http://www.planalto.gov.br/ccivil_03/decreto/2001/d3956.htm. Acesso em 05 out. 2020.

BRASIL. Decreto $\mathbf{n}^{\mathbf{0}} \mathbf{5 . 6 2 6}$, de 22 de dezembro de 2005, que regulamenta a Lei no 10.436, de 24 de abril de 2002, que dispõe sobre a Língua Brasileira de Sinais - Libras, e o art. 18 da Lei no 10.098, de 19 de dezembro de 2000, 2005. Disponível em: http://www.planalto.gov.br/ccivil_03/_ato2004-2006/2005/decreto/d5626.htm. Acesso em 05 out. 2020. 


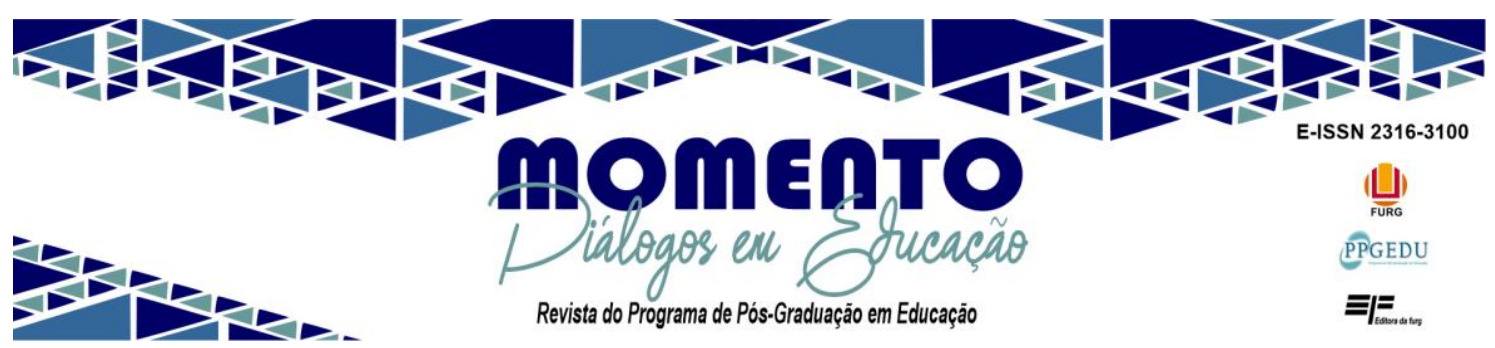

BRASIL. Decreto $\mathbf{n}^{0}$ 6949, de 25 de agosto de 2009, que promulga a Convenção Internacional sobre os Direitos das Pessoas com Deficiência e seu Protocolo Facultativo, assinados em Nova York, em 30 de março de 2007. Disponível em: http://www.planalto.gov.br/ccivil_03/_ato2007-2010/2009/decreto/d6949.htm. Acesso em: 03 ago. 2020.

BRASIL. Lei de Diretrizes e Bases da Educação Nacional no 9.394, de 20 de dezembro de 1996, estabelece as diretrizes e bases da educação nacional. Brasília: MEC Disponível em: http://www.planalto.gov.br/CCIVIL_03/leis/L9394.htm. Acesso em: 03 ago. 2020.

BRASIL. Lei no 10.172, de 9 de janeiro de 2001, aprova o Plano Nacional de Educação e dá outras providências. Brasília: Senado Federal 2001b. Disponível em: http://www.planalto.gov.br/ccivil_03/leis/leis_2001/110172.htm. Acesso em: 05/10/2020.

BRASIL. Lei $\mathbf{n}^{0}$ 10.436, de 24 de abril de 2002, que dispõe sobre a Língua Brasileira de Sinais - Libras e dá outras providências. Brasília: Senado Federal, 2002a. Disponível em: http://www.planalto.gov.br/ccivil_03/leis/2002/L10436.htm. Acesso em: 05/10/2020.

BRASIL. Lei $\mathbf{n}^{\mathbf{0}}$ 10.845, de 5 de março de 2004, que Institui o Programa de Complementação ao Atendimento Educacional Especializado às Pessoas Portadoras de Deficiência, e dá outras providências. Brasília: Senado Federal, 2004. Disponível em: http://portal.mec.gov.br/seesp/arquivos/pdf/lei10845.pdf. Acesso em: 05 out. 2020.

BRASIL. Lei no 13.005, de 25 de junho de 2014, aprova o Plano Nacional de Educação - PNE e dá outras providências. Brasília: Senado Federal, 2014. Disponível em: http://www.planalto.gov.br/ccivil_03/_ato2011-2014/2014/lei/113005.html. Acesso em: 05 out. 2020.

BRASIL. Lei $\mathbf{n}^{\mathbf{0}} \mathbf{7 . 8 5 3}$, de 24 de outubro de 1989, dispõe sobre o apoio às pessoas portadoras de deficiência, sua integração social, sobre a Coordenadoria Nacional para Integração da Pessoa Portadora de Deficiência (Corde) e institui a tutela jurisdicional de interesses coletivos ou difusos dessas pessoas, disciplina a atuação do Ministério Público, define crimes, e dá outras providências. Brasília: Senado Federal, 1989. Disponível em: http://www.planalto.gov.br/ccivil_03/LEIS/L7853.html. Acesso em: 05 out. 2020.

BRASIL. Lei n⿳0 8.069, de 13 de julho de 1990, dispõe sobre o Estatuto da Criança e do Adolescente e dá outras providências. Brasília: Senado Federal, 1990. Disponível em: http://www.planalto.gov.br/ccivil_03/LEIS/L8069.html. Acesso em: 05 out. 2020.

BRASIL. Lei no 13.146 de 6 de julho de 2015. Lei Brasileira de Inclusão da Pessoa com Deficiência (Estatuto da Pessoa com Deficiência). Disponível em: http://www.planalto.gov.br/ccivil_03/_ato2015-2018/2015/lei/113146.html. Acesso em: 05 out. 2020.

BRASIL. Ministério da Educação e do Desporto. Parâmetros curriculares nacionais adaptações curriculares: estratégias de ensino para educação de alunos com necessidades educacionais especiais. Secretaria de Educação Fundamental/Secretaria de Educação Especial. SEF/SEESP: Brasília, 1998. 


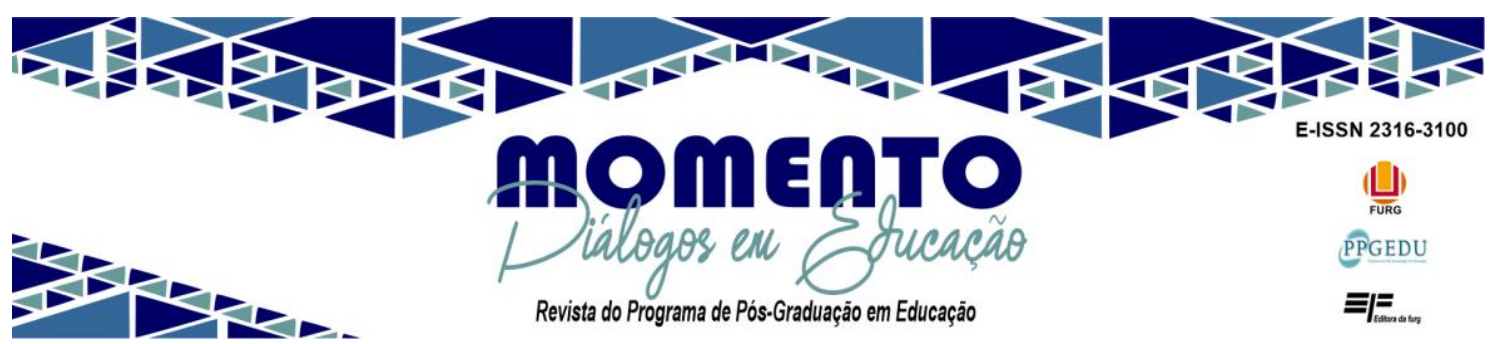

BRASIL. Ministério da Educação. Secretaria de Educação Especial. Política Nacional de Educação Especial. Brasília: MEC/SEESP, 1994b.

BRASIL. O Marco de Ação de Dakar Educação Para Todos: atendendo nossos Compromissos Coletivos. Dakar, Senegal: Cúpula Mundial de Educação, 2000. Disponível em: http://unesdoc.unesco.org/images/0012/001275/127509porb.pdf. Acesso em: 03 ago. 2020.

BRASIL. Parâmetros Curriculares Nacionais (Ensino Médio). Brasília: MEC/CEB, 2000. Disponível em: http://portal.mec.gov.br/seb/arquivos/pdf/14_24.pdf. Acesso em: 03 ago. 2020.

BRASIL. PCN+Ensino Médio, Orientações Educacionais Complementares aos Parâmetros Curriculares Nacionais (MEC-SEMTEC, 2002). Brasília: MEC/CEB, 2002. Disponível em: http://www.sbfisica.org.br/arquivos/PCN_CNMT.pdf. Acesso em: 03 ago. 2020.

BRASIL. Política Nacional de Educação Especial na Perspectiva Inclusiva. Brasília: 2008.

em:

http://peei.mec.gov.br/arquivos/politica_nacional_educacao_especial.pdf. Acesso em: 03 ago. 2020.

BRASIL. Resolução CNE/CP 1, de 18 de fevereiro de 2002, que Institui Diretrizes Curriculares Nacionais para a Formação de Professores da Educação Básica, em nível superior, curso de licenciatura, de graduação plena. Disponível em: http://portal.mec.gov.br/cne/arquivos/pdf/rcp01_02.pdf. Acesso em: 03 ago. 2020.

BRASIL. Resolução $\mathbf{n}^{0}$ 2, de 11 de setembro de 2001, institui Diretrizes Nacionais para a Educação Especial na Educação Básica. Brasília: MEC/CNE/CEB, 2001b. Disponível em: http://portal.mec.gov.br/cne/arquivos/pdf/CEB0201.pdf. Acesso em: 03 ago. 2020.

BRASIL. Resolução no 4, de 02 de outubro de 2009, institui diretrizes operacionais para o atendimento educacional especializado na Educação Básica, modalidade Educação Especial. Brasília: MEC/CNE/CEB, 2009. Disponível em: http://portal.mec.gov.br/dmdocuments/rceb004_09.pdf. Acesso em: 03 ago. 2020.

D’AMBRÓSIO, U. Os novos paradigmas e seus reflexos na destruição de certos mitos hoje prevalentes na educação. Educação Brasileira. Brasília: Crub (34): 33-47, $1^{\text {0 }}$ s., 1995.

DELORS, J. et al (org.) Educação um tesouro a descobrir: relatório para a UNESCO da Comissão Internacional sobre Educação para o século XXI. SP: Cortez; Brasília: UNESCO/MEC, 1998.

FORQUIN, J. C. Escola e cultura: as bases sociais e epistemológicas do conhecimento escolar. Trad. G. L. Louro. Porto Alegre: Artes Médicas, 1993.

GALLO, S. Conhecimento, transversalidade e educação. Impulso, out. 1997, p.116-121.

KUHN, T. S. A estrutura das revoluções científicas. Trad. B. V. Boeira e N. Boeira. 3. Ed. São Paulo: Perspectiva, 1991.

LIPPE, E. M; ALVES, F. S.; CAMARGO, E. P. Análise do processo inclusivo em uma escola estadual no município de Bauru: a voz de um aluno com deficiência visual. 


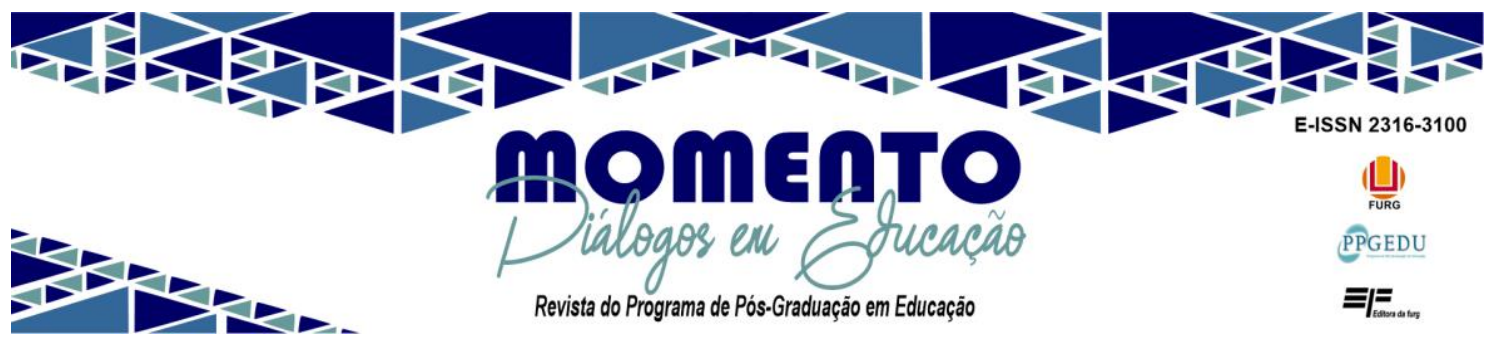

Revista Ensaio, v. 14, n. 2, p. 81-94, 2012.

MANTOAN, M. T. É. Inclusão escolar. O que é? Por quê? Como fazer? São Paulo; Ed. Moderna, 2003.

MANTOAN, M. T. É. O desafio das diferenças nas escolas. Rio de Janeiro; Ed Vozes Ltda, 2008.

PAETZOLD, G. J. P.; NOGUEIRA, S. V. (Re) visitando o conceito de educação inclusiva: marco legal e sentidos pedagógicos. In: HAHN, Noli Bernardo; OLIVEIRA, Kathlen Luana de; REBLIN, Iuri Andréas. (Org.). Direito a ter direitos: diálogos entre Direito, Cultura e Religião. 1ed. São Leopoldo/RS: EST/FURI, 2016, v. 01, p. 219-231.

QUEIROZ, T. G. B. et al. Estudo de planejamento e design de um módulo instrucional sobre o Sistema Respiratório: o ensino de ciências para surdos. Ciência \& Educação, v.18, n. 4, p. 913-930, 2012.

SACRISTÁN, J. G. Currículo e diversidade cultural. In: SILVA, T. T. da \& MOREIRA, A. F. B. (Org.). Territórios contestados: o currículo e os novos mapas políticos e culturais. Petrópolis, Vozes, 1995, p. 82-113.

SILVA, T. T.; MOREIRA, A. F. (org.). Territórios contestados: os novos mapas políticos e culturais. Petrópolis: Vozes, 1995.

SILVA, T. T. Documentos de identidade: uma introdução às teorias do currículo. Belo Horizonte: Autêntica, 1999.

SOUZA, R. de F. Currículo e conhecimento: a contribuição das teorias críticas. Revista de Educação. São Paulo: APEOSP, 1999, p. 17-20.

STAINBACK, S.; STAINBACK, W. Inclusão: um guia para educadores. Trad. Magda França Lopes. Porto Alegre: Artes Médicas, 1999.

TYLER, R. W. Princípios básicos de currículo e ensino. Porto Alegre: Globo, 1974.

UNESCO. Declaração de Nova Delhi sobre Educação Para Todos. Nova Delhi- Índia: Unesco, 1993. Disponível

em: http://unesdoc.unesco.org/images/0013/001393/139393por.pdf. Acesso em: 03/08/2020.

UNESCO. Declaração Mundial sobre Educação Para Todos (Conferência de Jomtien). Tailândia: Unesco, $1990 . \quad$ Disponível em: http://www.unicef.org/brazil/pt/resources_10230.html. Acesso em: 03 ago. 2020.

UNESCO. O Marco de Ação de Dakar Educação Para Todos: atendendo nossos Compromissos Coletivos. Dakar, Senegal: Cúpula Mundial de Educação, 2000. Disponível em: http://unesdoc.unesco.org/images/0012/001275/127509porb.pdf. Acesso em: 03 ago. 2020.

VIEGAS, L. T. Educação Inclusiva: políticas, pesquisa e formação. Porto Alegre: EDIPUCRS, 2012.

Submissão em: 30-10-2019

Aceito em: 11-10-2020 